\title{
Structural transitions of the metal-oxide nodes within metal-organic frameworks: On the local structures of NU-1000 and UiO-66
}

Ana E. Platero-Prats, ${ }^{\dagger}$ Andreas Mavrantonakis, ${ }^{\circledR}$ Leighanne C. Gallington, ${ }^{+}$Yangyang Liu, ${ }^{\psi}$ Joseph T. Hupp, ${ }^{\psi}$ Omar K. Farha, ${ }^{\psi,}{ }^{\ddagger}$ Christopher J. Cramer, ${ }^{\S}$ Karena W. Chapman ${ }^{*},+$

${ }^{+}$X-ray Science Division, Advanced Photon Source, Argonne National Laboratory, Argonne, Illinois 60439, United States

${ }^{\S}$ Department of Chemistry, Chemical Theory Center, and Supercomputing Institute, University of Minnesota, 207 Pleasant Street SE, Minneapolis, MN 55455-0431, United States

${ }^{*}$ Department of Chemistry, Northwestern University, 2145 Sheridan Road, Evanston, Illinois 60208-3113, United States

${ }^{\ddagger}$ Department of Chemistry, Faculty of Science, King Abdulaziz University, Jeddah, Saudi Arabia

\section{Supporting Information}

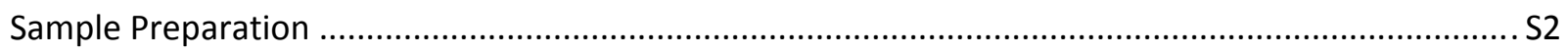

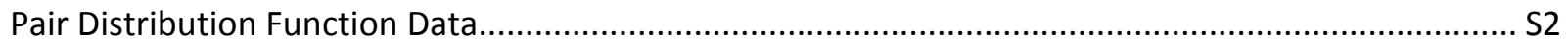

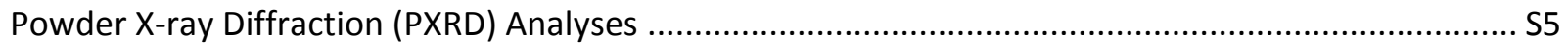

Differential Scanning Calorimetry (DSC) and Thermogravimertic Analyses (dTGA) ............................S7

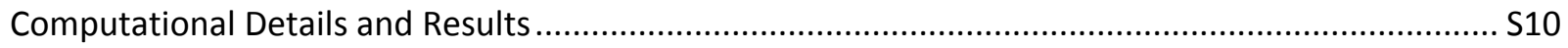

Orientation of the $\mathrm{M}_{6}(\mathrm{O})_{8}$ Nodes in UiO-66 and NU-1000 Frameworks......................................... S16

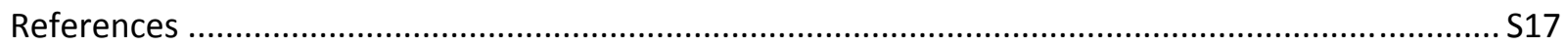




\section{Sample Preparation}

$\mathrm{Zr}-\mathrm{NU}-1000,{ }^{1} \mathrm{Hf}-\mathrm{NU}-1000,{ }^{2} \mathrm{Zr}-\mathrm{UiO}-66,{ }^{3}$ and Hf-UiO- $66^{4}$ were synthesized according to methods reported in the literature. Benzoic acid capped $\mathrm{Zr}_{6} \mathrm{O}_{8}$ cluster was prepared by modified method as follows: ${ }^{5}$ An $80 \%$ solution of $\mathrm{Zr}(\mathrm{OPr})_{4}$ in $\mathrm{n}$-Butanol (Aldrich, as received) was mixed under an Ar atmosphere with a solution of benzoic acid in n-propanol. The mixture was refluxed for $2 \mathrm{~h}$ during which a white solid precipitate appeared. The solid was isolated and dried under vacuum.

\section{Pair Distribution Function Data}

Below $300{ }^{\circ} \mathrm{C}$, the changes to the PDF in the region of the $\mathrm{Zr}$...Zr correlation are well fit by varying the height and width of 3 Gaussian functions at fixed distances of 3.53(1) $\AA$, 3.33(10) $\AA$ and 3.72(10) $\AA$. Above $300{ }^{\circ} \mathrm{C}$, where the peak at $3.7 \AA$ shifts to longer distance, the Gaussian function was also allowed to refine to longer distance. Differential PDFs (dPDFs) were calculating by subtracting the PDF for the original material at the control temperature (i.e. $50^{\circ} \mathrm{C}$ ) from the heat treated PDF. $\left(G(r)(T)-G(r)\left(T_{0}\right)\right)$

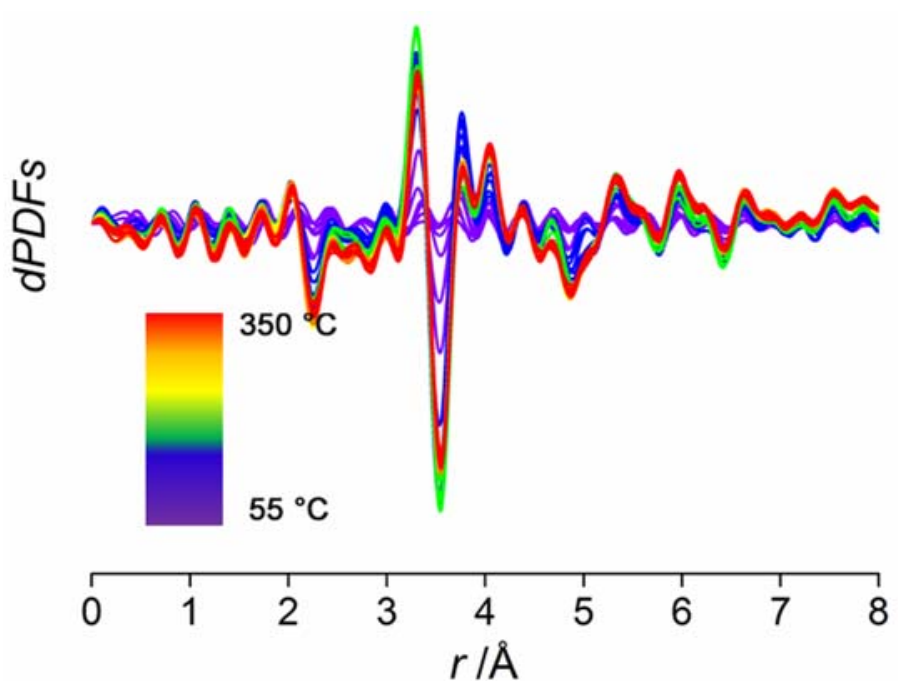

Figure S1: Experimental dPDFs for Zr-NU-1000.

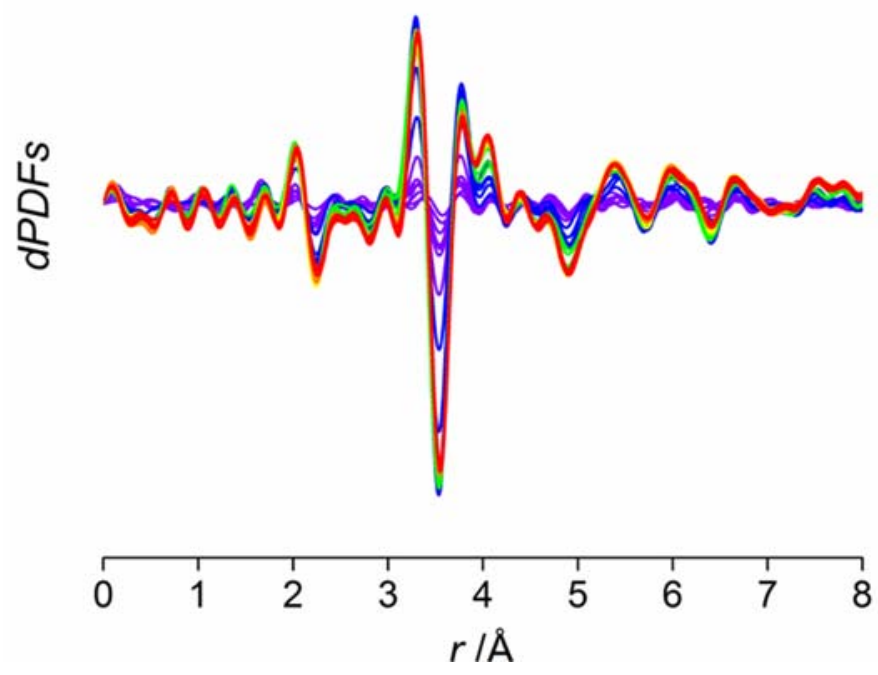

Figure S2: Experimental dPDFs for Zr-UiO-66.
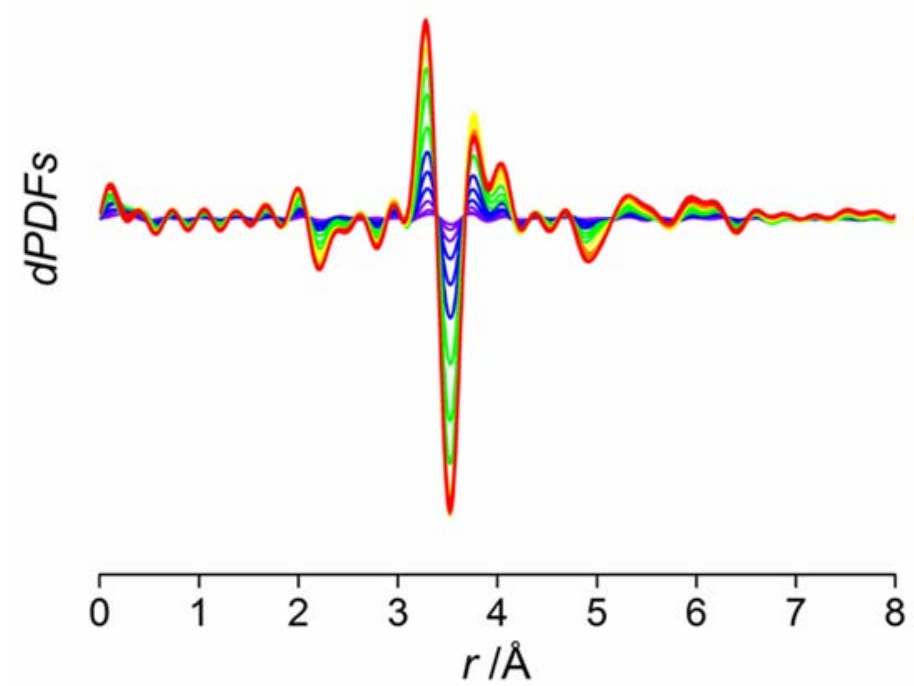

Figure S3: Experimental dPDFs for Hf-NU-1000.

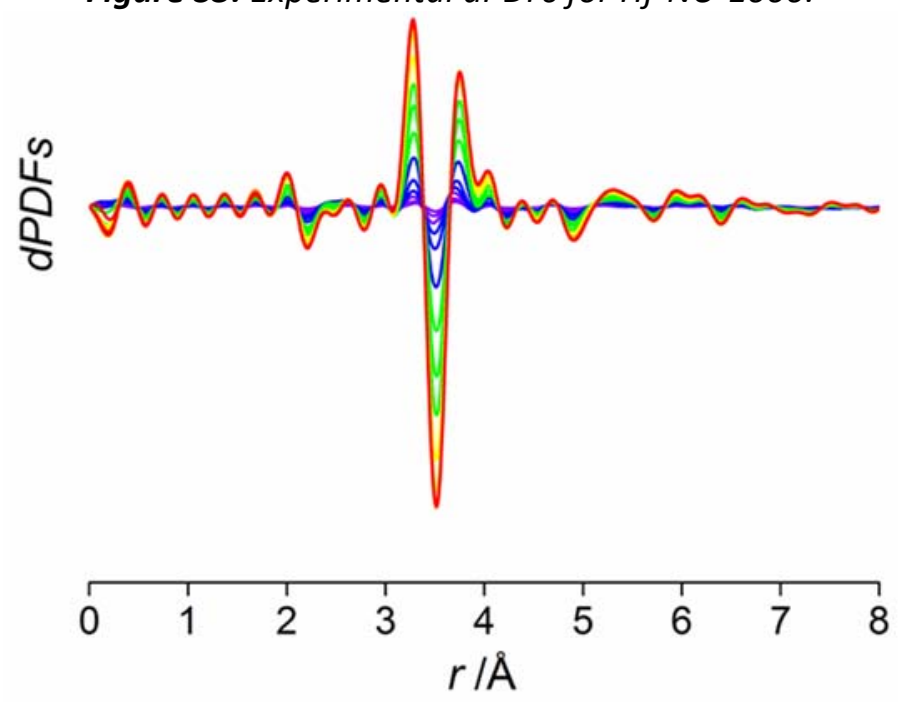

Figure S4: Experimental dPDF for Hf-UiO-66. 
Table S1: Experimental M...M and M-O determined from in-situ PDF for NU-1000 and UiO-66 materials.

\begin{tabular}{cccc}
\hline MOF & $T /{ }^{\circ} \mathrm{C}$ & M...M distance/ $\AA^{[a]}$ & M-O distance $/ \AA^{[b]}$ \\
\hline Zr-NU-1000 & 50 & 3.53 & 2.19 \\
Hf-NU-1000 & 50 & 3.51 & 2.17 \\
Zr-UiO-66 & 50 & 3.53 & 2.20 \\
Hf-UiO-66 & 50 & 3.51 & 2.18 \\
\hline Zr-NU-1000 & 350 & $3.32,3.79,4.05$ & 2.12 \\
Hf-NU-1000 & 350 & $3.28,3.77,4.03$ & 2.11 \\
Zr-UiO-66 & 350 & $3.31,3.78,4.04$ & 2.12 \\
Hf-UiO-66 & 350 & $3.28,3.75,4.05$ & 2.14 \\
\hline
\end{tabular}

[a] Values determined from differential PDFs. ${ }^{[b]}$ Values determined from total PDFs.

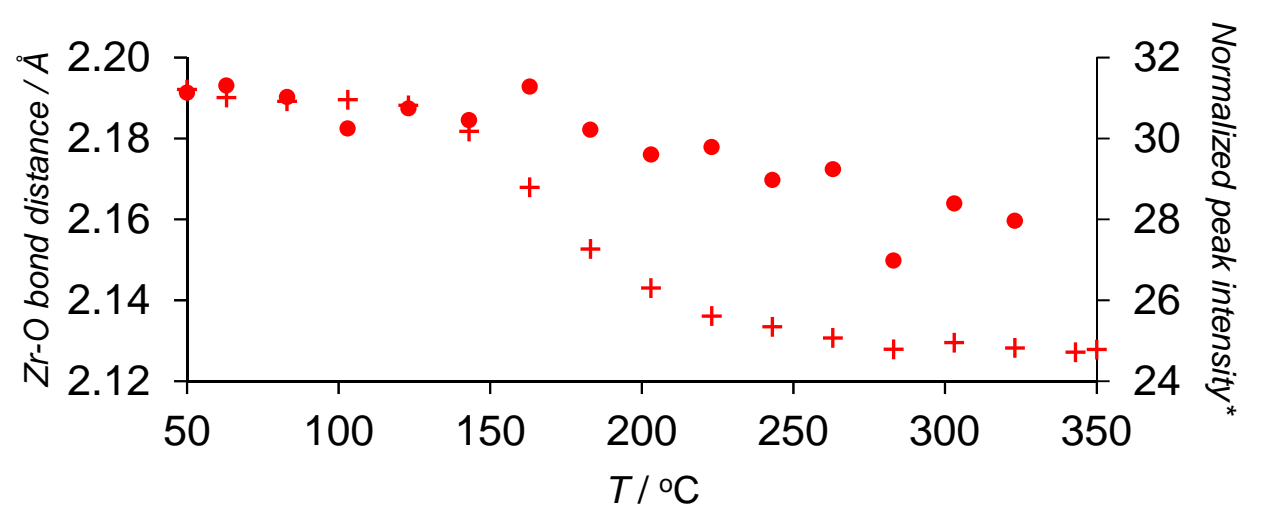

*Peak intensity normalized to $32 \mathrm{Zr}$-O bonds.

Figure S5: Changes in the Zr-O distances determined by in-situ PDF on Zr UiO-66.

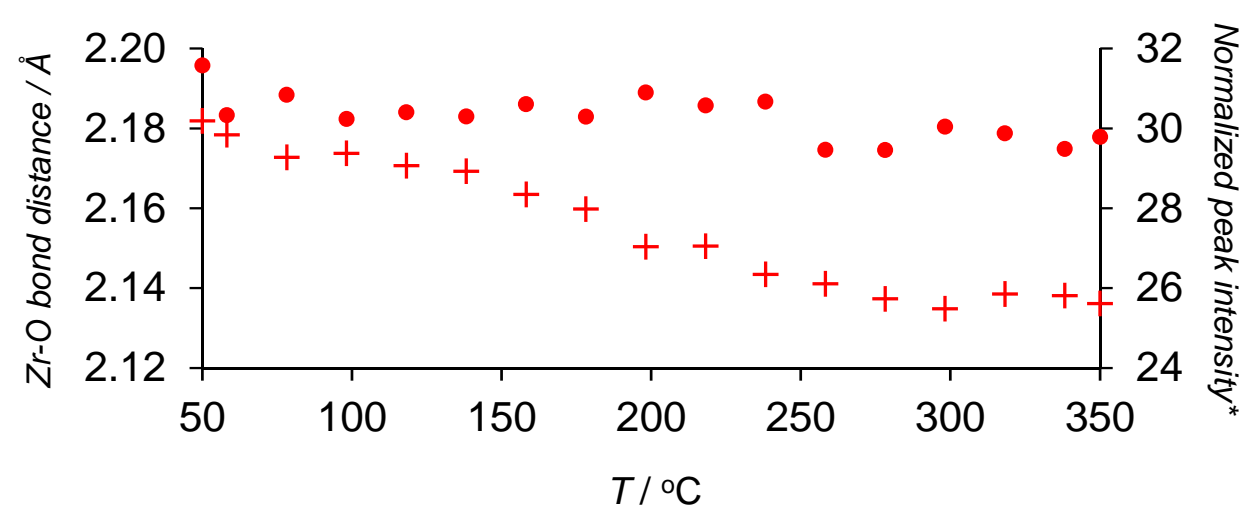

${ }^{*}$ Peak intensity normalized to $32 \mathrm{Zr}$-O bonds.

Figure S6: Changes in the Zr-O distances determined by in-situ PDF on Zr UiO-66. 


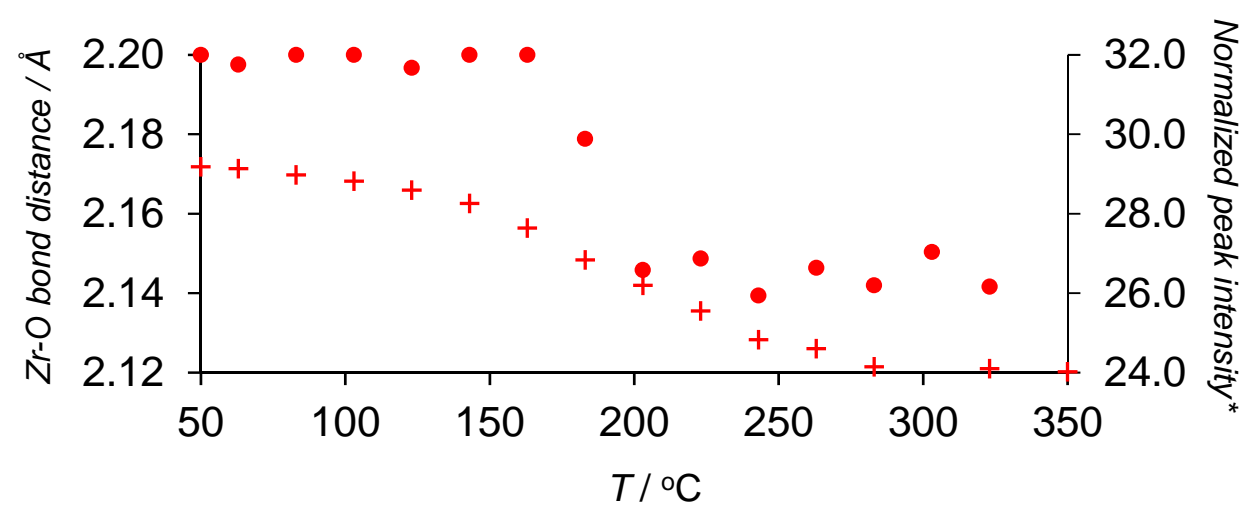

*Peak intensity normalized to $32 \mathrm{Zr}$-O bonds.

Figure S7: Changes in the Zr-O distances determined by in-situ PDF on Zr NU-1000.

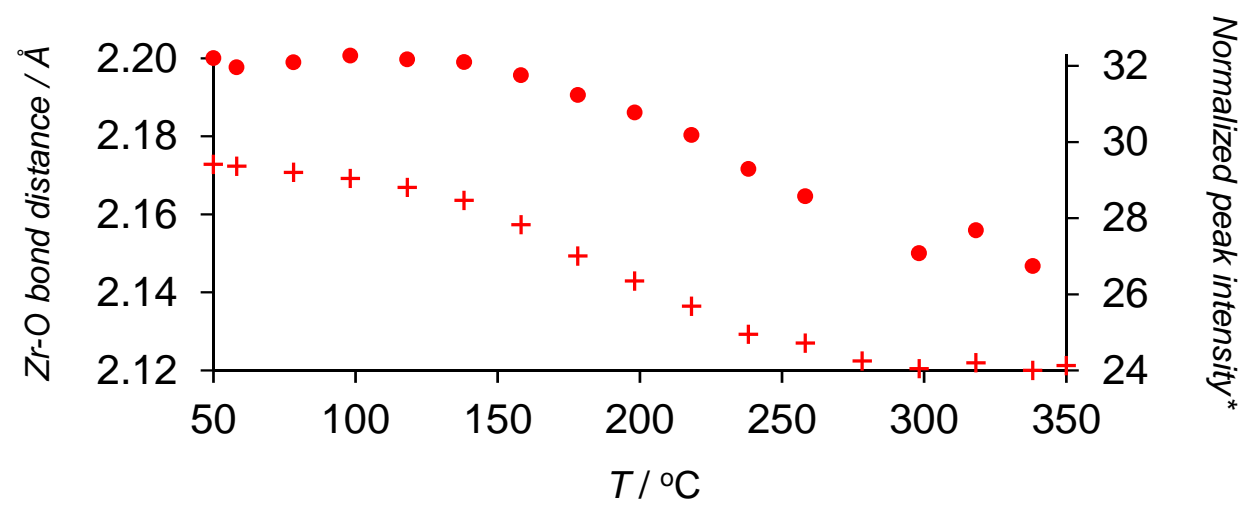

*Peak intensity normalized to $32 \mathrm{Zr}$-O bonds.

Figure S8: Changes in the Zr-O distances determined by in-situ PDF on Hf NU-1000. 
Powder X-ray Diffraction (PXRD) Analyses
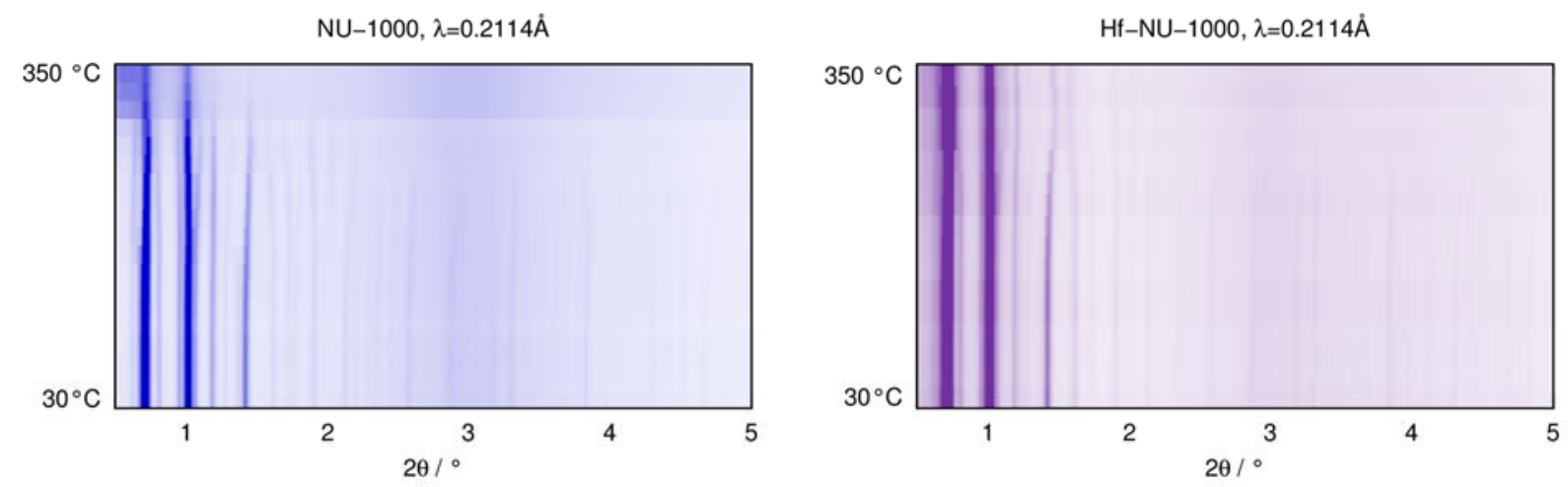

UiO- $66, \lambda=0.2114 \AA$

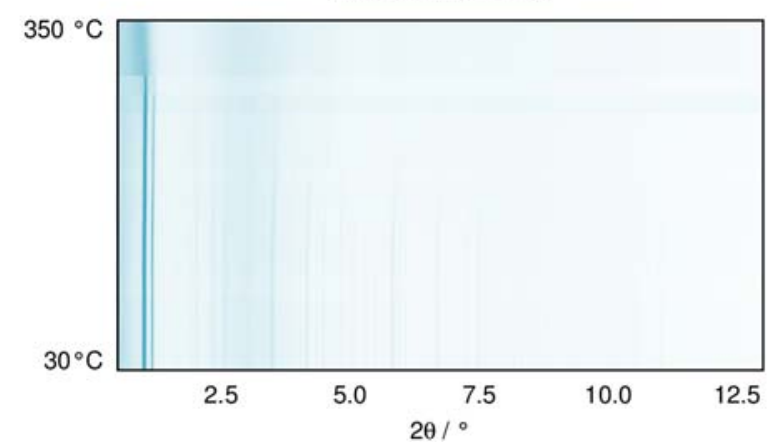

HfUiO-66, $\lambda=0.2114 \AA$

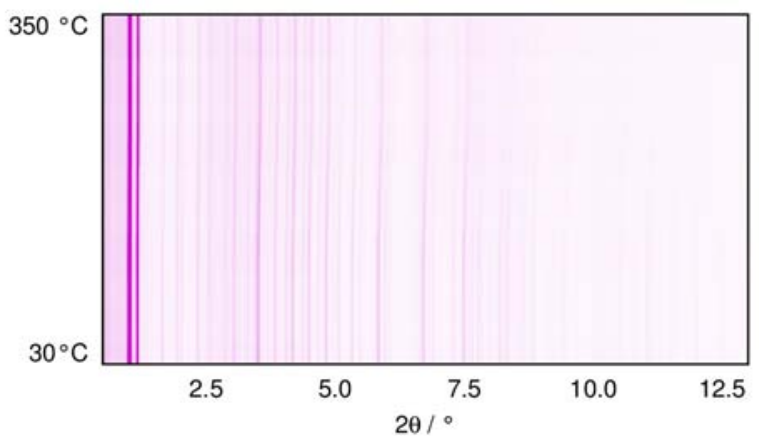

Figure S9: PXRD patterns of NU-1000, UiO-66, and their $\mathrm{Hf}$ analogues upon heating to $350^{\circ} \mathrm{C}$.
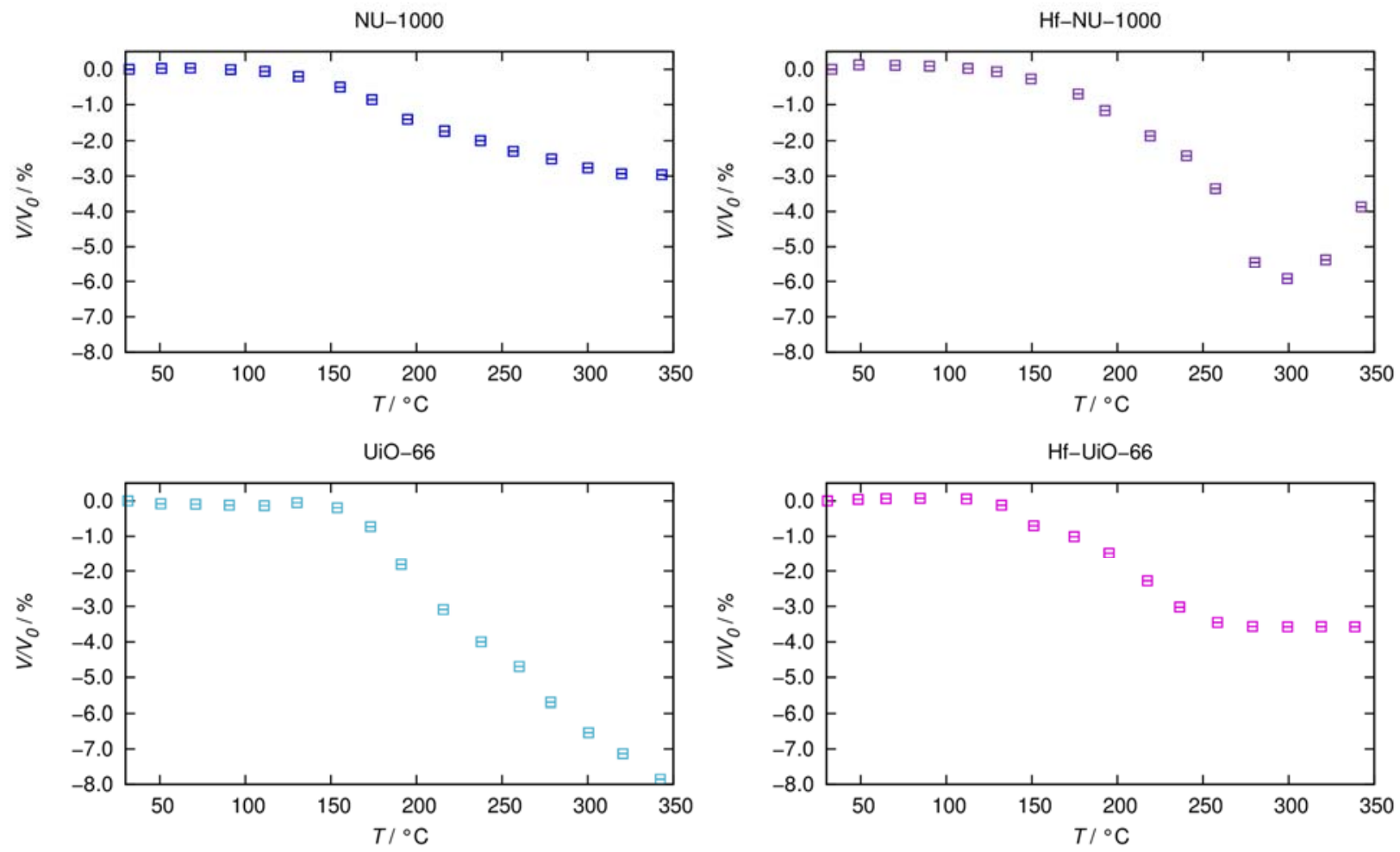

Figure S10: Normalized volumetric contraction of NU-1000, UiO-66, and their Hf analogues upon heating to $350^{\circ} \mathrm{C}$. 

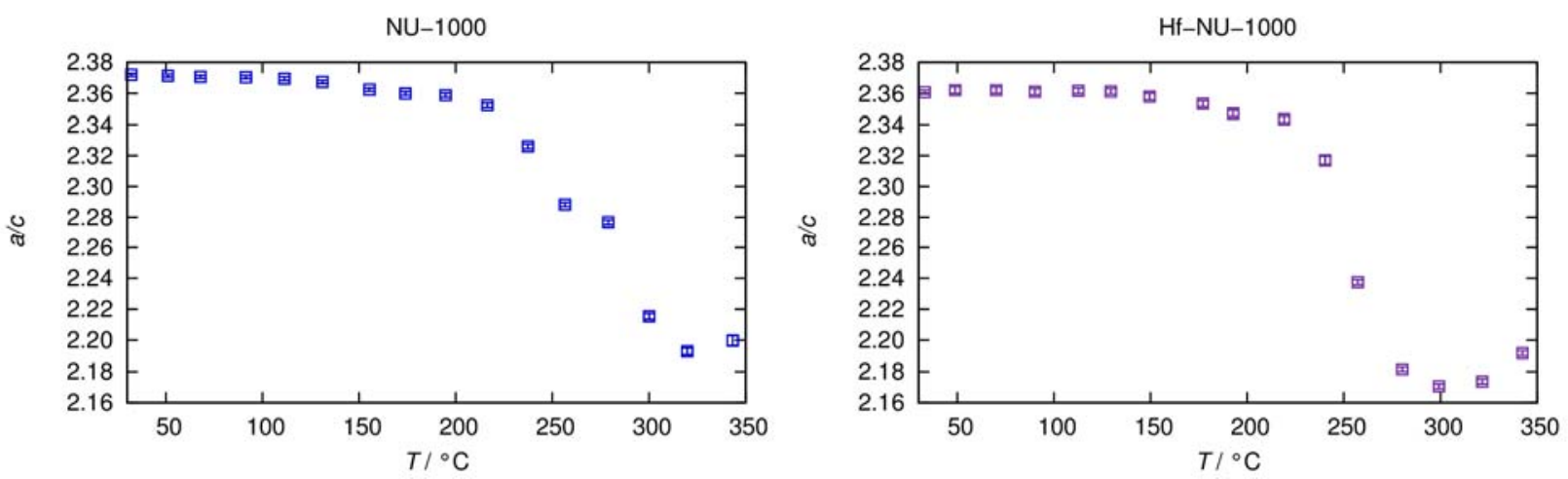

Figure S11: a/c variation on NU-1000 materials heating to $350^{\circ} \mathrm{C}$. 


\section{Differential Scanning Calorimetry (DSC) and Thermogravimertic Analyses (dTGA)}

DSC profiles for NU-1000 materials show two endothermic peaks below $300^{\circ} \mathrm{C}$. The first one, centered at 165 and $155^{\circ} \mathrm{C}$ for $\mathrm{Zr}$ - and $\mathrm{Hf} \mathrm{NU}-1000$, respectively, can be assigned to the first regime of the distortion (i.e. 1:1 short to long distances ratio). The second one, much broader, suggests the coexistence of several endothermic processes, and is associated to the further regimes distortion determined at high temperatures. This second DSC peak has its maximum signal at 242 and $248{ }^{\circ} \mathrm{C}$ for $\mathrm{Zr}$ - and $\mathrm{Hf} \mathrm{NU}-1000$, respectively. UiO-66 materials show a single sharp endothermic DSC peak at 180 and $160^{\circ} \mathrm{C}$ for $\mathrm{Zr}$ - and $\mathrm{Hf}$-materials, respectively, which can be assigned to the first regime of the distortion.

Zr NU-1000

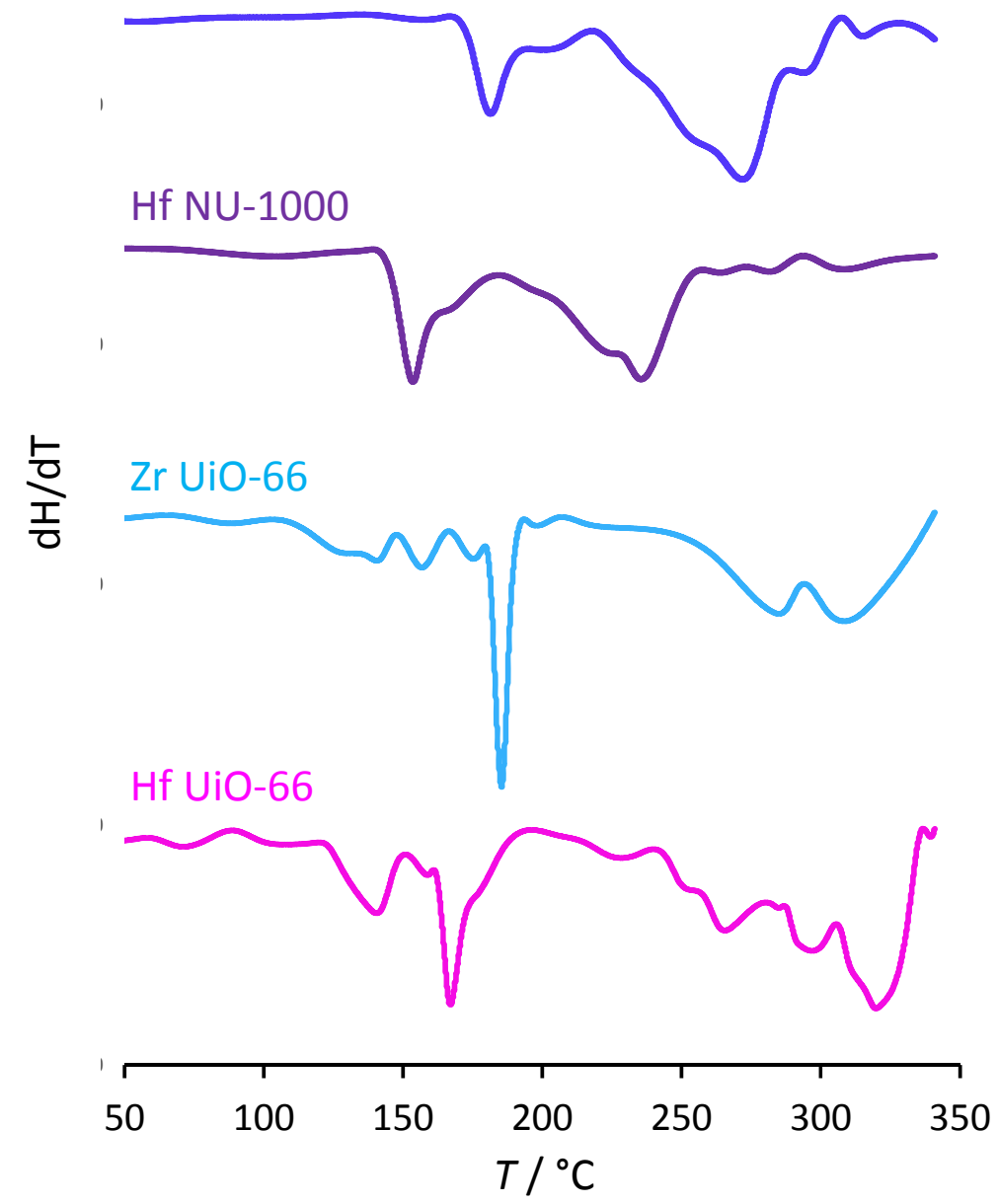

Figure S12. DSC profiles for NU-1000 and UiO-66 materials from 50 to $350^{\circ} \mathrm{C}$. 


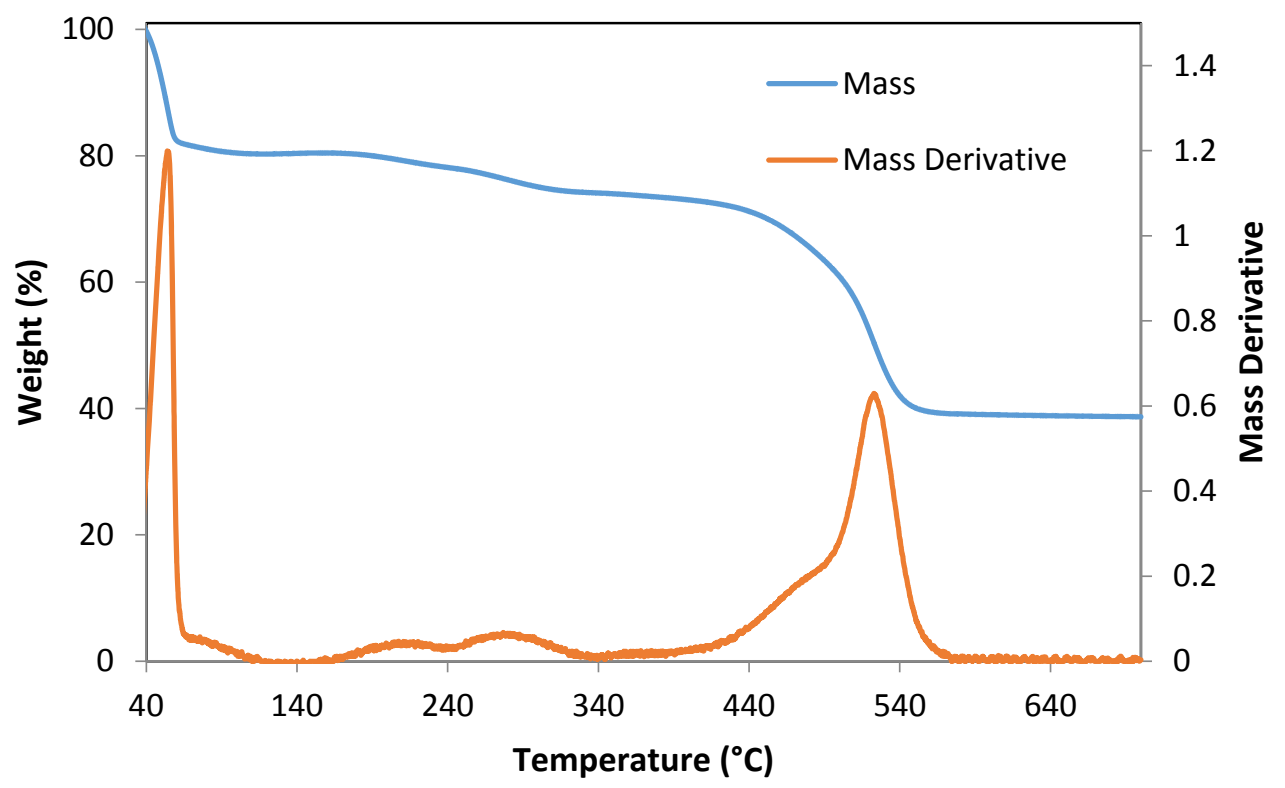

Figure S13. TGA and first derivative of TGA (dTGA) of Zr-UiO-66

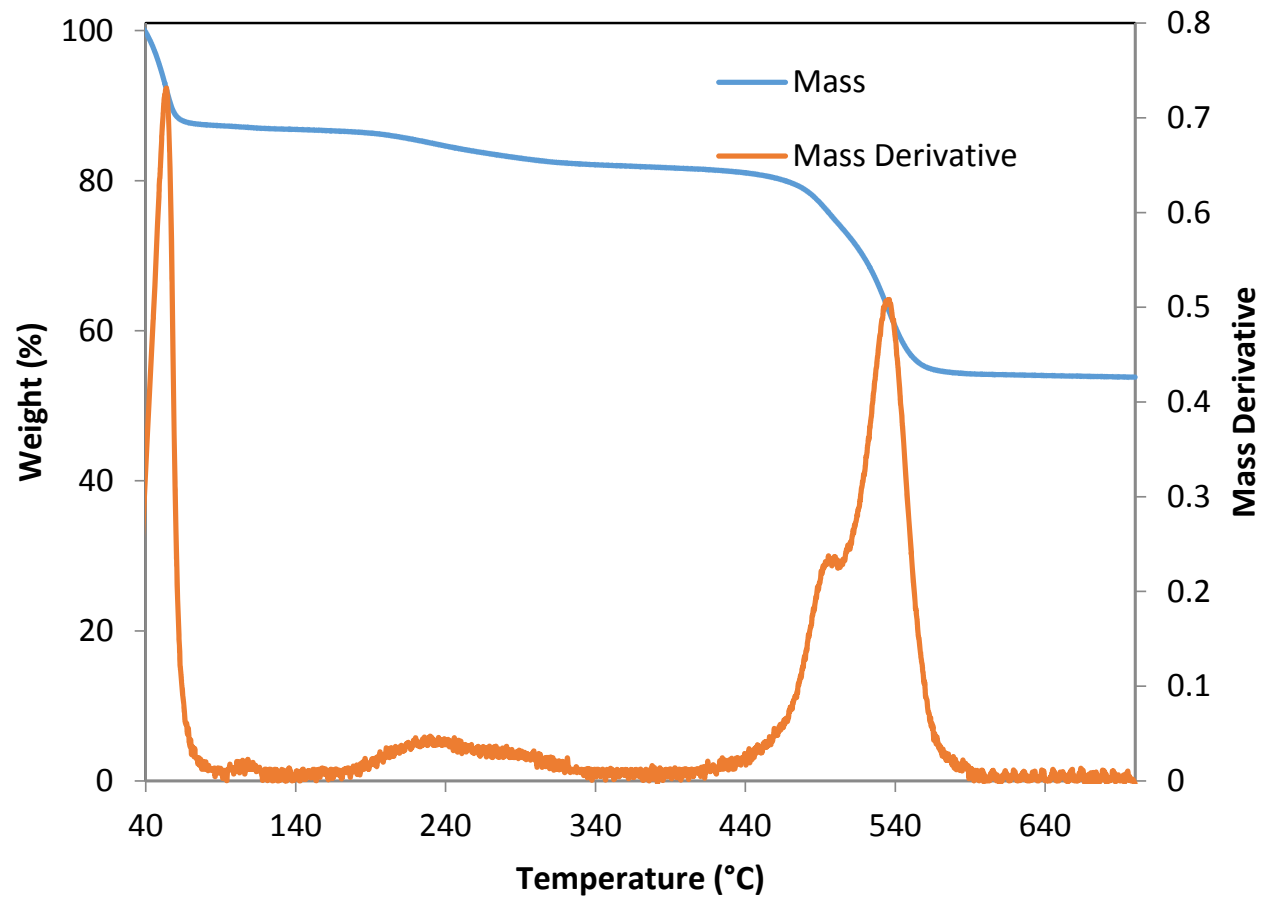

Figure S14. TGA and first derivative of TGA (dTGA) of Hf-UiO-66 


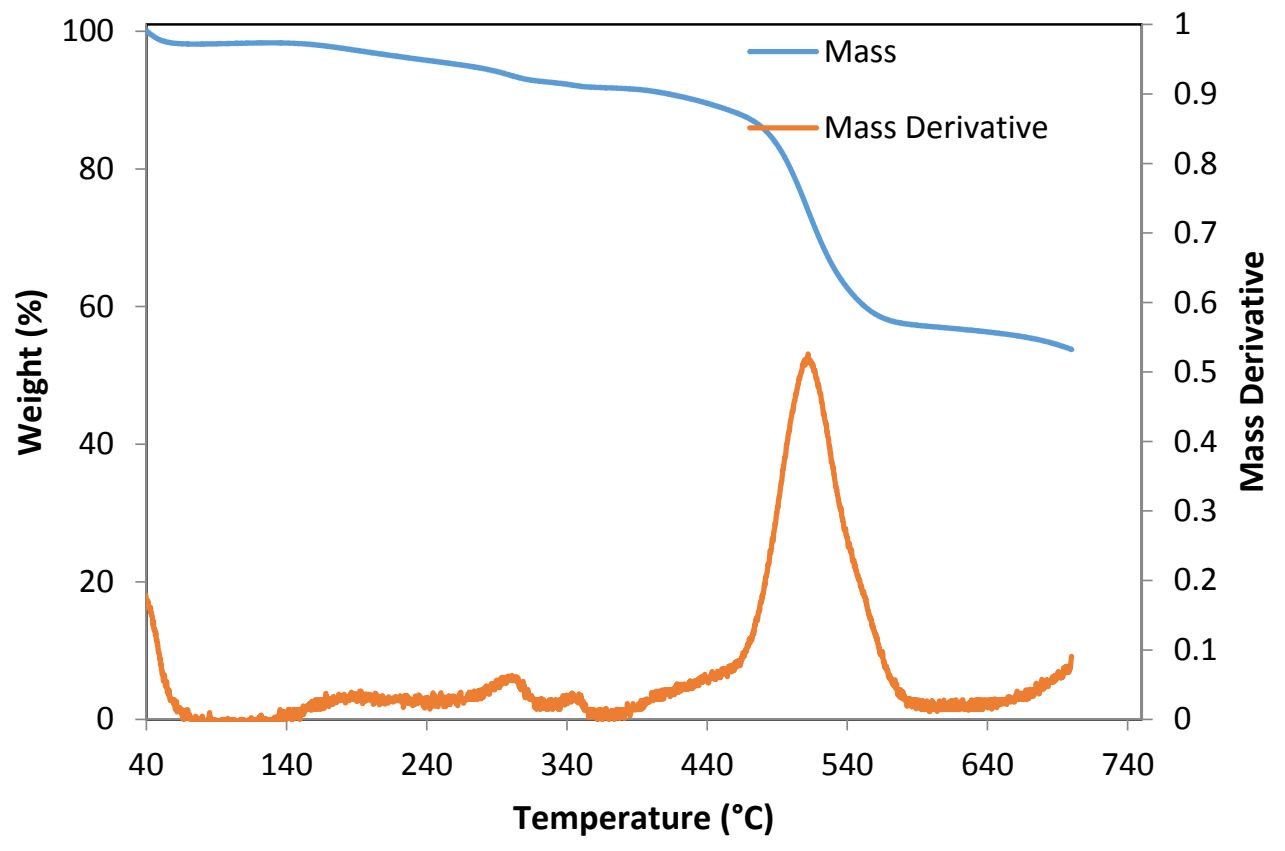

Figure S15. TGA and first derivative of TGA (dTGA) of Zr-UiO-1000

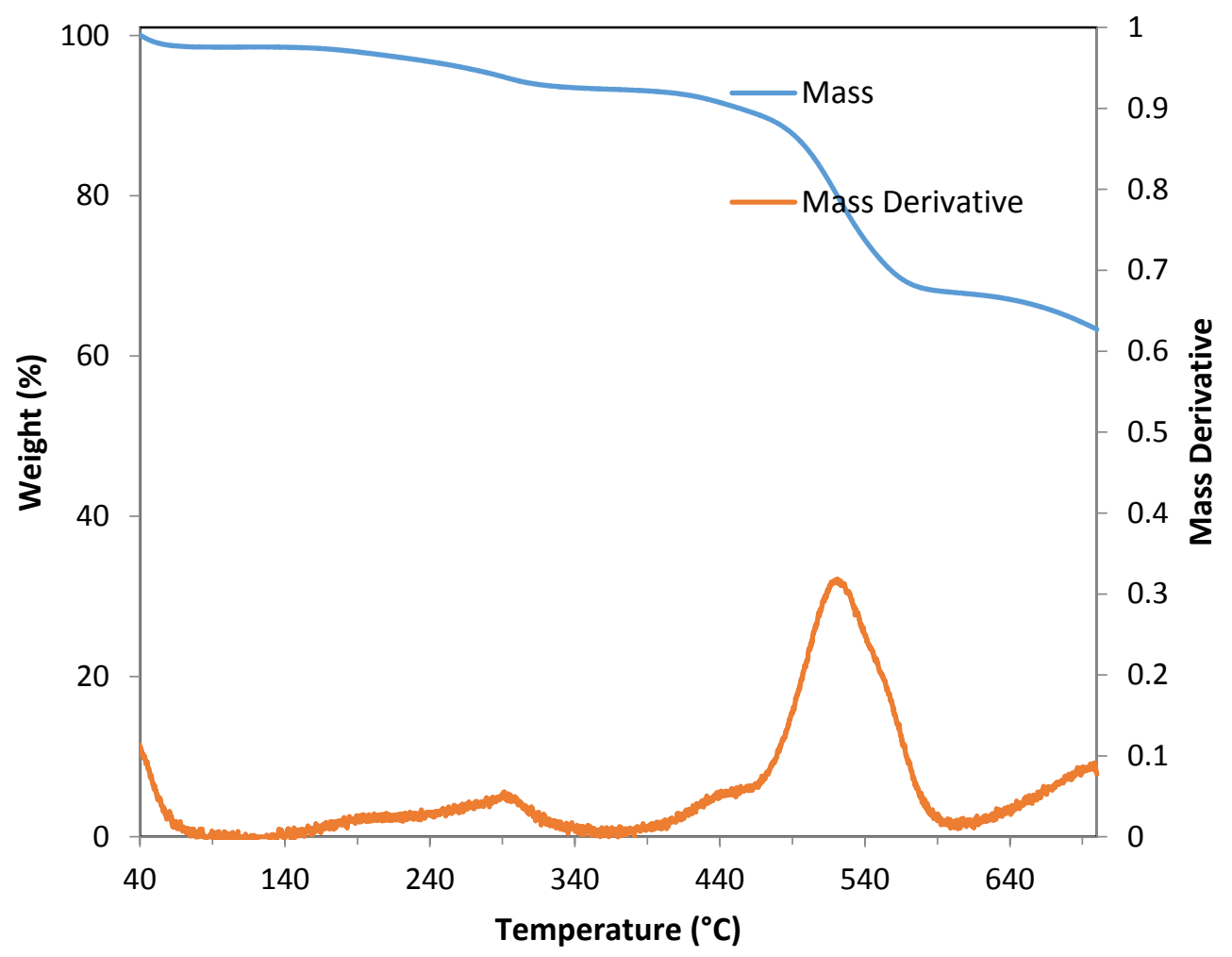

Figure S16. TGA and first derivative of TGA (dTGA) of Hf-UiO-1000. 


\section{Computational Details and Results}

The structure of $\mathrm{Zr}-\mathrm{NU}-1000$ was modeled both as a periodic structure and as a molecular cluster. Two molecular cluster models varying in size were used. The first model $(\mathrm{m}-\mathrm{I})$ consists of the $\mathrm{Zr}_{6} \mathrm{O}_{8}$ core capped with eight formate anions, whereas the larger model (m-II) has the $\mathrm{Zr}_{6} \mathrm{O}_{8}$ core capped with eight 4biphenyl-carboxylate groups. Both models are presented in Figure S17.

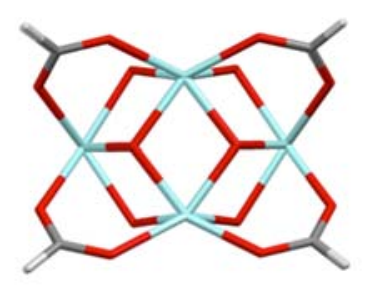

$\mathrm{m}-\mathrm{I}$

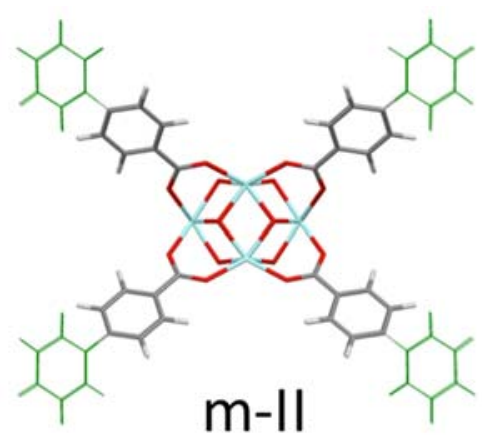

$\mathrm{m}-\mathrm{II}$

Figure S17: $m$-I and m-II molecular models of NU-1000 used in this work. Atoms that are kept frozen during geometry optimizations, are shown in green.

To identify accessible structural distortions, ab initio molecular dynamics based on the canonical ensemble were performed for the smaller model $\mathrm{m}-\mathrm{I}$ at temperatures ranging from $500 \mathrm{~K}$ to $1500 \mathrm{~K}$. The initial structure for the MD was chosen to have the mixed proton topology determined previously. ${ }^{6}$ The most common distortion patterns observed along the molecular dynamics trajectory were taken as initial structures for subsequent geometry optimizations. These calculations employed the gradient corrected Perdew-Burke-Ernzerhofer $(\mathrm{PBE})^{7}$ functional as implemented in Turbomole 6.5. ${ }^{8}$ For the dynamics simulations, the Stuttgart-Dresden effective core potential was used, which assumes 28 electrons in the core region for $\mathrm{Zr}^{9}{ }^{9}$ For lighter atoms, the smaller def-SV(P) basis set was used for the dynamics simulations, while the more complete def2-TZVP ${ }^{10}$ basis set was used for subsequent geometry optimizations. Optimizations were performed with the PBE and M06- $\mathrm{L}^{11}$ functionals.

DFT calculations with periodic boundary conditions were carried out using the PBE exchange-correlation functional as implemented in the VASP program package. ${ }^{12,13}$ Core electrons were described within the projector augmented wave (PAW) scheme. For $\mathrm{C}$ and $\mathrm{O}$, the $2 \mathrm{~s}$ and $2 p$ electrons are treated explicitly; for $\mathrm{Zr}$, the $4 s, 4 p, 5 s$ and $4 d$ electrons are included (together with the $\mathrm{Zr}$ _sv PAW pseudopotential). The core radii for $\mathrm{Zr}, \mathrm{O}, \mathrm{C}$ and $\mathrm{H}$ were 2.50, 1.52, 1.50 and 1.10 a.u. respectively. The valence electrons were described by a plane wave basis set with a kinetic energy cutoff of $520 \mathrm{eV}$. In all optimizations, the cell parameters and ionic positions were relaxed until the forces were smaller than $0.02 \mathrm{eV} / \mathrm{A}$. The convergence criteria for the electronic step were set to $10^{-5} \mathrm{eV}$. These computational details were also used in our previous work establishing the proton topology of NU-1000. Error! Reference source not found.

Enthalpies and Gibbs free energies were calculated based on the quantum mechanical harmonic-oscillator approximation for the vibrational partition function (the rotational and translational partition functions are neglected for the periodic solid). Due to the size of the unit cell, a partial hessian was calculated, taking into account only the atoms of the $\mathrm{Zr}_{6} \mathrm{O}_{8}$ core. Harmonic force constants were calculated numerically by displacing each atom by a negative and positive stepsize of $0.01 \AA$ in all three cartesian directions. The convergence criterion for the electronic step was set to $10^{-6} \mathrm{eV}$ for the calculation of harmonic force constants. 
Thermodynamic free energy contributions were also calculated for the $\mathbf{m}$-II model. During the geometry optimizations, the eight phenyl rings were kept frozen (in positions dictated by the corresponding pyrene units in the actual linkers of $\mathrm{NU}-1000$ ) and only the $\mathrm{Zr}_{6} \mathrm{O}_{8}$ core and the connecting benzoate ligands were allowed to change their positions. Frequency analysis confirmed all final structures as local minima. For the geometry optimizations, the PBE (Turbomole) and M06-L Error! Reference source not found. (Gaussian 09) ${ }^{14}$ functionals were used in combination with the def2-SVP basis set. As a final step, the final electronic energies were calculated using the larger def2-TZVP basis set.

Results: Based on the results from the molecular dynamics simulations, several distortions of a dehydrated model ( $\mathrm{m}-\mathrm{I})$ were created with $\mu_{3}-\mathrm{O}$ atoms moved so as to become $\mu_{2}-\mathrm{O}$ or even terminal-O. These geometries were optimized at the PBE and M06L/def2-TZVP level. Four low-energy isomers (I to IV) are shown in Figure S18 together with their relative energies at the PBE/def2-TZVP, MP2/def2TZVP//PBE/def2-TZVP, M06-L/def2-TZVP and MP2/def2-TZVP//M06-L/def2-TZVP levels. For clarity, the $\mu_{3}-\mathrm{O}$ atoms (from the symmetrical conformation) that have changed their coordination numbers are shown in black. Four new conformers were identified with relative energies ranging over $185 \mathrm{~kJ} / \mathrm{mol}$. Since, PBE and M06L showed a difference of up to $40 \mathrm{~kJ} / \mathrm{mol}$ for the relative energies, we decided to perform MP2/def2-TZVP single point energy calculations on the optimized geometries, in order to get a more accurate estimate of relative energies. As presented in Figure S18, the M06-L values are very close to the MP2 values, thus indicating that it is more appropriate for calculating the relative energies of the distorted conformations.

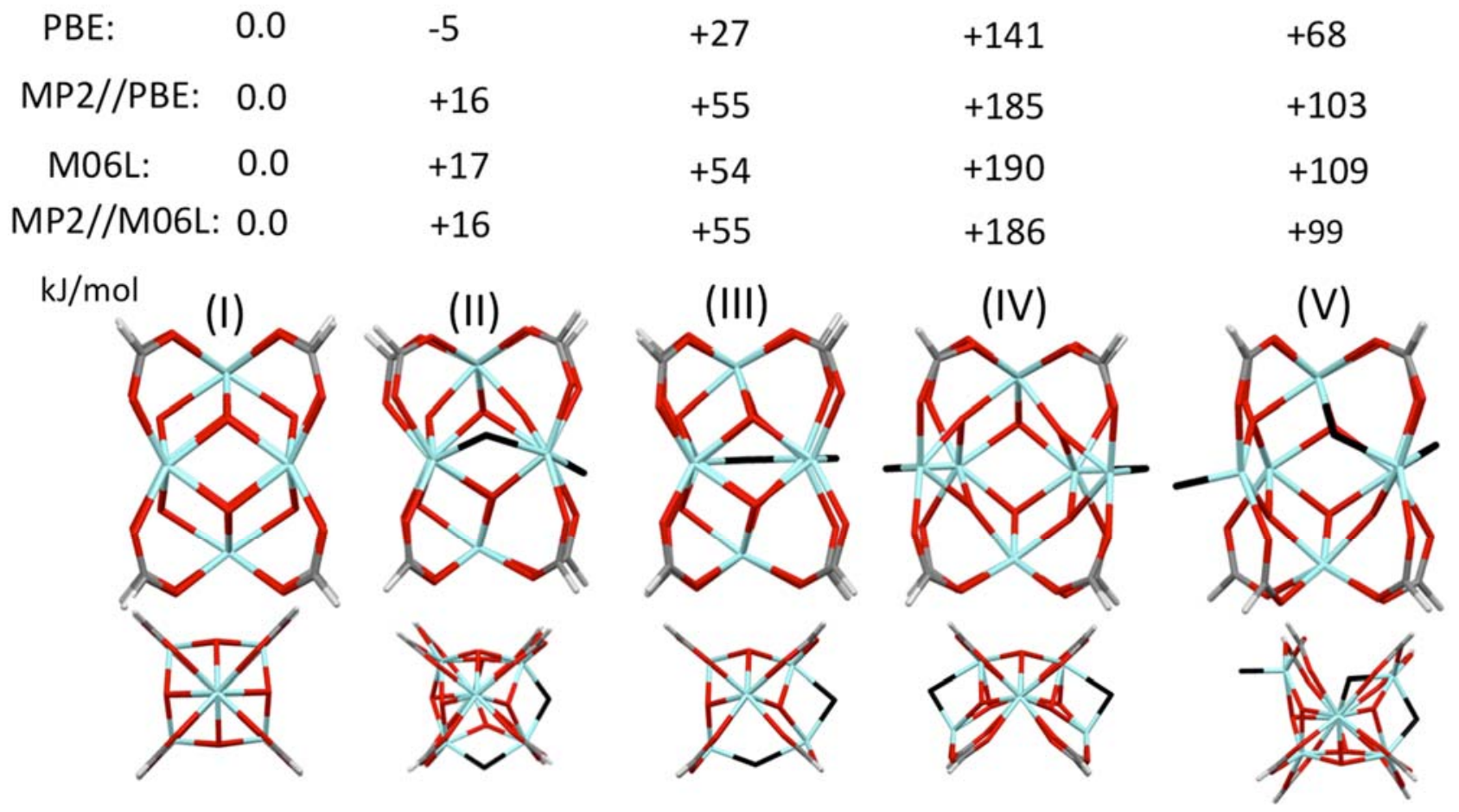

Figure S18: Low-lying isomers of the $\mathrm{Zr}_{6} \mathrm{O}_{8}$ core of $\mathrm{NU}-1000$, capped with formate anions. For clarity, $\mu_{3}-\mathrm{O}$ atoms are shown in black. The symmetric ("cubic-type") isomer is considered as reference point. All energy differences are in $\mathrm{kJ} / \mathrm{mol}$. Optimizations are performed at PBE and M06-L/def2-TZVP level, followed by single point energy calculations with the MP2/def2-TZVP method. 
A common observation in three of these conformers is that two of the core oxygen atoms are $\mu_{2}$ coordinated, while in the fifth isomer (V) a third $\mathrm{O}$ atom is removed from the core entirely and becomes a terminal-oxo, leaving a "hole" in the original core. The fifth conformer, while being $100 \mathrm{~kJ} / \mathrm{mol}$ higher in energy than the symmetrical one at the MP2/def2-TZVP//M06-L/def2-TZVP and MP2/def2-TZVP//PBE levels, provides the best match with the experimentally observed ratio of short:long $\mathrm{Zr}-\mathrm{Zr}$ bonds.

We next created periodic structures of $\mathrm{NU}-1000$ having all $\mathrm{Zr}_{6} \mathrm{O}_{8}$ cores replaced by those determined for II to $\mathbf{V}$ (as noted above, periodic I was already in hand). We also examined a $\mathrm{Zr}_{6} \mathrm{O}_{8}$ core cut from the monoclinic phase of bulk zirconia. The lattice parameters and atomic positions were then optimized with PBE as implemented in the VASP program. The three "best" structures together with their lattice parameters and relative energies are presented in Figure $\mathbf{S 1 9}$ and Table S2. The distorted-core structures (2) and (3) are predicted to be less stable than the "cubic-type" I by 62 and $130 \mathrm{~kJ} / \mathrm{mol}$, respectively.
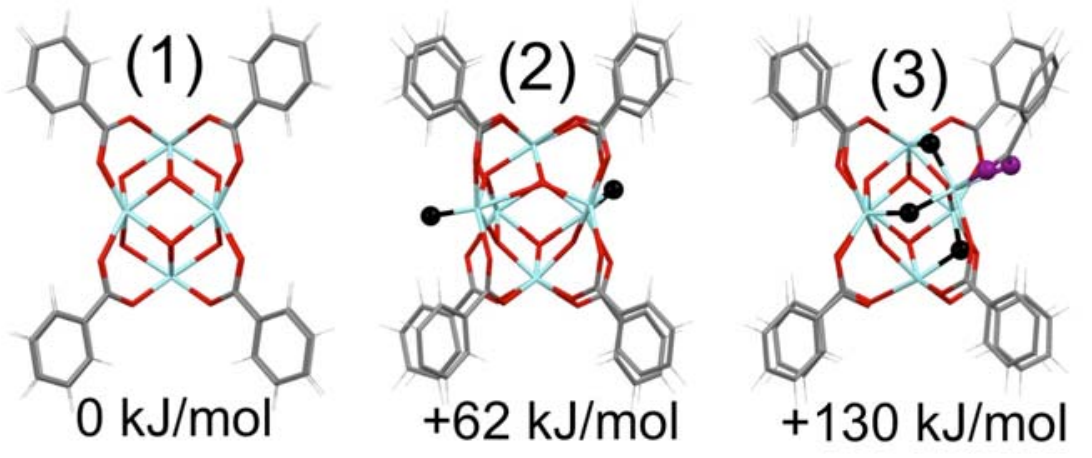

Figure S19: Periodic structures of NU-1000 with three different conformations of the $\mathrm{Zr}_{6}$-core and their PBE relative energies per node calculated with VASP. (1) is the "cubic-type", (2) is the "monoclinic-type" conformation and in (3) one of the ligands has changed coordination mode to bidentate chelate. For clarity, $\mu_{3}-\mathrm{O}$ atoms are shown in black. In conformation (3), the ligands that has changed the coordination mode, is shown in purple.

The best structural match to the experimental PDF is conformer (2), which has 7 short Zr-Zr bonds of 3.17 to $3.47 \AA$, 4 long of 3.57 to $3.93 \AA$ and 1 extra-long of $4.34 \AA$. It has structural similarities to the monoclinic phase of bulk zirconia, so we will refer to this as the "monoclinic-type" conformation.

When using as initial guess for the node the coordinates of the monoclinic zirconia, the framework structure was computed to be less stable by $390 \mathrm{~kJ} / \mathrm{mol}$ than the symmetrical conformation, or by a value of $130 \mathrm{~kJ} / \mathrm{mol}$ when normalizing per zirconia core. In this distorted conformation, one of the linkers has changed the coordination mode from bidentate bridging to bidentate chelating, as shown in Figure S21. The linker coordinates to only one zirconium atom. It has 8 short $\mathrm{Zr}-\mathrm{Zr}$ bonds of 3.17 to $3.47 \AA$ and 3 long of 3.56 to $3.96 \AA$. Similar rearrangements of the ligands have been reported in hexa-zirconium oxide clusters, analogous to the UiO-66, by using NMR spectroscopy and MD simulations. (Ref: PCCP, 2009, 11, 3640-3647, DOI: $10.1039 / \mathrm{b} 820731 \mathrm{c}$ ) The authors showed that the chelate coordination mode is $40 \mathrm{~kJ} / \mathrm{mol}$ higher in energy compared to the bridging mode. In the case of the NU-1000, the restrictions imposed by the framework do not allow flexibility of the ligands, thus making such rearrangement highly unfavorable compared to the isolated zirconium oxide clusters. 
Table S2: Lattice cell parameters and volumes for Zr-NU-1000 for different conformations of the nodes, as shown in Figure S18.

\begin{tabular}{|l|l|l|l|l|l|}
\hline & $a, b(\AA)$ & $c(\AA)$ & $\alpha, \beta\left(^{\circ}\right)$ & $\gamma\left({ }^{\circ}\right)$ & $V\left(\AA^{3}\right)$ \\
\hline (1): “cubic-type" & 38.56 & 17.25 & 90 & 120 & 22224 \\
\hline (2): “monoclinic-type" & 38.34 & 17.39 & $91.1,89$ & 120 & 22135 \\
\hline$(3)$ & $\begin{array}{l}38.18, \\
38.05\end{array}$ & 17.33 & $90.2,91.3$ & 120.2 & 21758 \\
\hline
\end{tabular}

The optimized lattice parameters for the distorted node (2) have a ratio of $a / c=2.20(a=38.34 \AA$ and $c=$ $17.39 \AA)$, which is in agreement with the experimental value $a / c=2.21$. This distorted cell is predicted to be $187 \mathrm{~kJ} / \mathrm{mol}$ higher in energy than the cell with the symmetrical $\mathrm{Zr}_{6} \mathrm{O}_{8}$ core. Since $\mathrm{NU}-1000$ contains three $\mathrm{Zr}_{6} \mathrm{O}_{8}$ cores per unit cell, this value should be normalized to $62 \mathrm{~kJ} / \mathrm{mol}$ per zirconia core. These results are summarized in Table S3. If thermal and entropic corrections at $500 \mathrm{~K}$ are taken into account, the percore relative free energy difference is reduced to $41 \mathrm{~kJ} / \mathrm{mol}$, although the enthalpic difference is $62 \mathrm{~kJ} / \mathrm{mol}$. Similar trends in relative thermodynamic quantities are predicted from molecular cluster calculations. PBE gives results within $10 \mathrm{~kJ} / \mathrm{mol}$ of those calculated for the periodic system. This good agreement between the results of the periodic and the cluster models suggests restraints employed in the latter reasonably reflect the periodic environment. Like the PBE functional, M06-L predicts the monoclinic-type node to be less stable than the cubic-type: At $500 \mathrm{~K}$, the free energy difference is predicted to be $67 \mathrm{~kJ} / \mathrm{mol}$. Coordinates for all periodic structures are provided in a separate file.

Table S3: Relative (free) energy and enthalpy differences (in $\mathrm{kJ} / \mathrm{mol}$ ) between the symmetrical (cubictype) and distorted (monoclinic-type) configuration of NU-1000. The cubic-type conformation is taken as the zero-reference point. Results are calculated from periodic calculations with PBE (VASP) and the $m$-II molecular models with PBE (Turbomole) \& MO6-L (Gaussian 09) and are normalized per $\mathrm{Zr}_{6} \mathrm{O}_{8}$ node.

\begin{tabular}{|l|l|l|l|}
\hline $\mathrm{kJ} / \mathrm{mol}$ & $\begin{array}{l}\mathrm{PBE} \\
(\mathrm{VASP})\end{array}$ & $\begin{array}{l}\mathrm{PBE} / \mathrm{def2}-\mathrm{TZVP} / / \\
\mathrm{PBE} / \mathrm{def} 2-\mathrm{SVP}\end{array}$ & $\begin{array}{l}\text { M06L/def2-TZVP// } \\
\text { M06L/def2-SVP }\end{array}$ \\
\hline & $(\mathrm{P})^{\mathrm{a}}$ & $(\mathrm{C})^{\mathrm{a}}$ & $(\mathrm{C})^{\mathrm{a}}$ \\
\hline$\Delta \mathrm{E}$ & +62 & +54 & +96 \\
\hline$\Delta \mathrm{H}(0 \mathrm{~K})$ & $+56^{\mathrm{b}}$ & $+48^{\mathrm{b}}$ & $+88^{\mathrm{c}}$ \\
\hline$\Delta \mathrm{H}(500 \mathrm{~K})$ & $+61^{\mathrm{b}}$ & $+52^{\mathrm{b}}$ & $+95^{\mathrm{c}}$ \\
\hline$\Delta \mathrm{G}(500 \mathrm{~K})$ & $+41^{\mathrm{b}}$ & $+36^{\mathrm{b}}$ & $+67^{\mathrm{c}}$ \\
\hline
\end{tabular}

a $(\mathrm{P})$ denotes calculations for periodic structure and (C) for molecular clusters.

${ }^{b}$ a partial Hessian from the 14 atoms of the zirconia core is taken into account.

c a partial Hessian from the zirconia core and the eight benzoate linkers is taken into account. 
We have compared these results with energetics predicted for the equivalent phases of bulk zirconia. The structures were obtained from the Materials Project ${ }^{14}$ database and calculated with the same input parameters that were used for NU-1000. For bulk zirconia, the cubic phase is predicted to be less stable than the monoclinic by $81 \mathrm{~kJ} / \mathrm{mol}$. The unit cell of bulk zirconia contains $4 \mathrm{Zr}$ and 80 atoms, while that of NU-1000 has $6 \mathrm{Zr}$ atoms per node, so it was normalized per zirconium atom basis. Thus, while for bulk zirconia the monoclinic phase is predicted to be more stable than the cubic by $20 \mathrm{~kJ} / \mathrm{mol}$ per $\mathrm{Zr}$, the relative stability of the two phase geometries is predicted to change in dehydro-NU-1000, with monoclinic being less stable by $11 \mathrm{~kJ} / \mathrm{mol}$ per $\mathrm{Zr}$.

The calculated free energy values represent an upper bound for the free energy difference between structures, because two factors cannot be easily quantified. The first factor is associated to the entropy of the distorted configuration within the context of the mesoporous solid. The distorted node will be associated with a significant increase in entropy not only for each node, but also given the distribution of asymmetric nodes within the now pseudo-periodic solid. The symmetric node can only take one spatial orientation. Given the fact that the oxygen dislocation has a preferable orientation perpendicular to the c $\neg$ axis, it can occupy any of two available equatorial positions, affording to two distinct spatial orientations. Accordingly, for the 3 nodes per unit cell, node distortion is associated with $2 \times 2 \times 2=8$ microstates. This high-degree of disorder in the resulting solid will increase its entropy so that the free energy will be reduced compared to the symmetric node. The second is the change in the PressureVolume factor, associated with the enthalpy change of the system. Because of the smaller volume of the distorted structure (22135 $\AA$ ) than the cubic-type (22224 $\AA$ ), this factor will favor the monoclinic type. Since, there is so defined pressure for solids, this factor cannot be quantified, but will eventually reduce the free energy difference between the two structures.
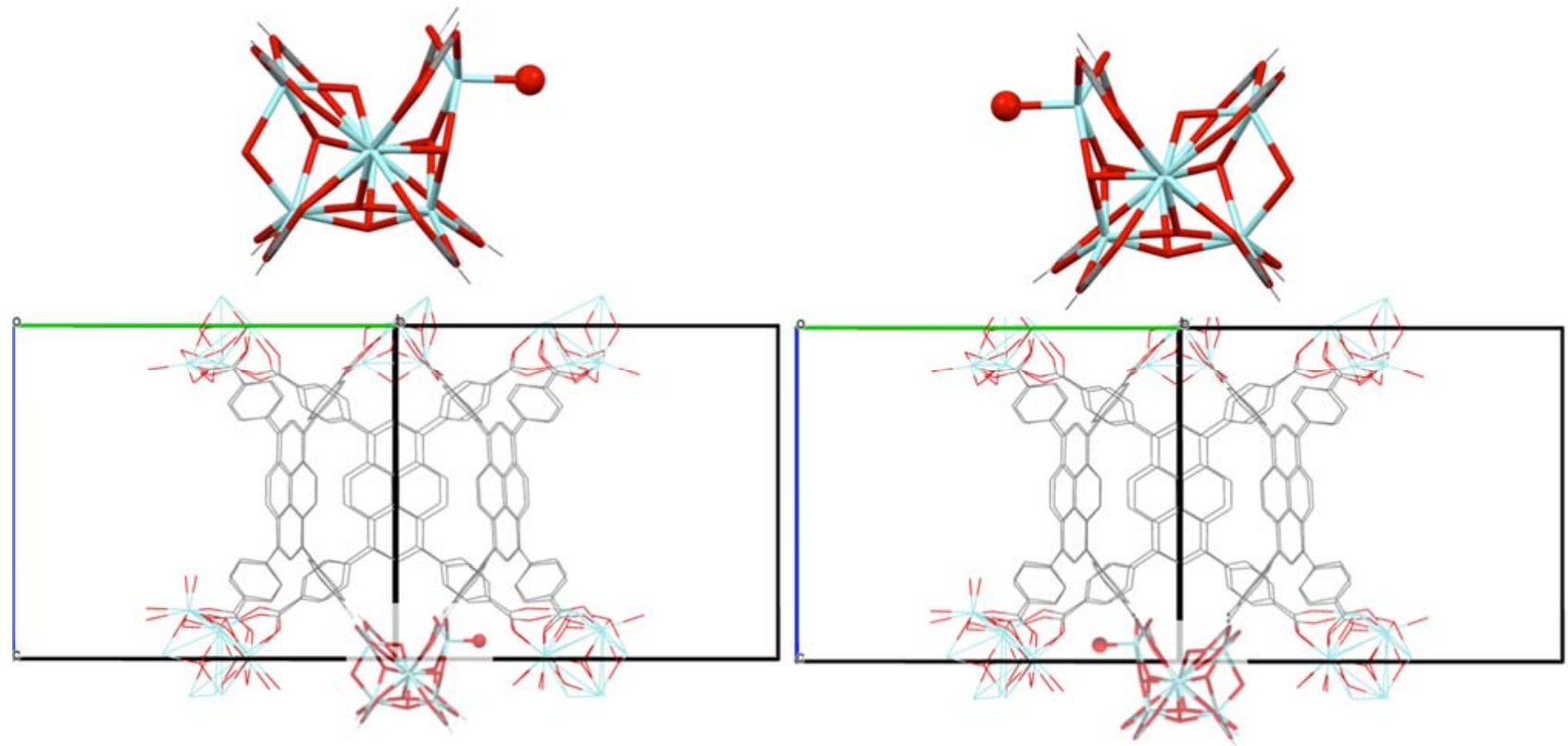

Figure S20: (Upper part) Rotation of the O-dislocation by $90^{\circ}$ along the axis of the $\mathrm{Zr}_{6}$ octahedron generates four spatial orientations. (Lower part) Two possible orientations of the oxygen dislocation in the periodic cell. 
We also investigated the case, where only one of the nodes is distorted while the other two remain symmetric. The resulting structure was $62 \mathrm{~kJ} / \mathrm{mol}$ higher in energy than the framework structure with three symmetric cores per unit cell. This indicates that the node distortion has an additive effect on the relative stability of the framework. In the distorted node, two of the core oxygen atoms became $\mu_{2}$ coordinated and a third $\mathrm{O}$ atom was removed from the core entirely and became a terminal-oxo, leaving a "hole" in the original core. The dislocated oxygen atom is oriented perpendicular to the c axis of the cell. We then investigated if the direction of the dislocated oxygen atom has an effect on the relative stability. The dislocation may occupy two possible unequal positions: along the c-axis or perpendicular. Thus a new conformation was created by applying a $90^{\circ}$ rotation along the axial $\mathrm{Zr}$ atoms of the pseudo-octahedron and placing the oxygen dislocation along the $c$-axis. After the geometry optimization, the new structure was computed to be $72 \mathrm{~kJ} / \mathrm{mol}$ higher in energy than the structure with all symmetric zirconia nodes and $10 \mathrm{~kJ} / \mathrm{mol}$ higher than the above-mentioned distorted structure. Thus, the node distortion shows a slightly favorable directionality in the pore. 
Orientation of the $\mathrm{M}_{6}(\mathrm{O})_{8}$ Nodes in UiO-66 and NU-1000 Frameworks

a) UiO-66

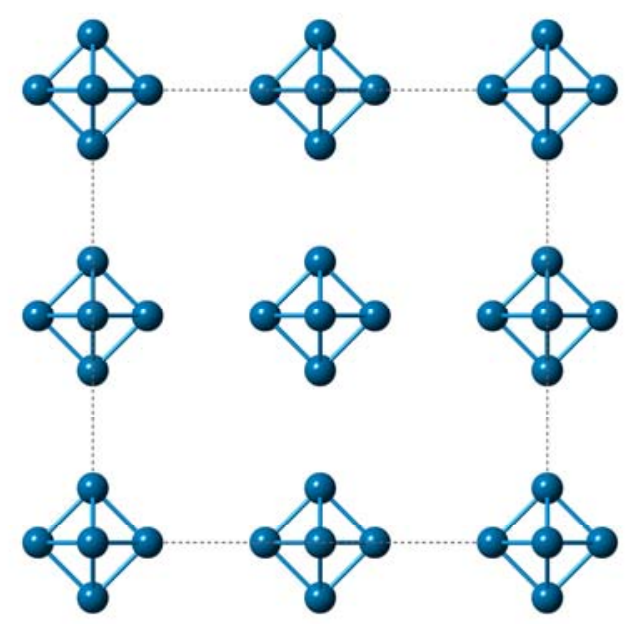

b) NU-1000

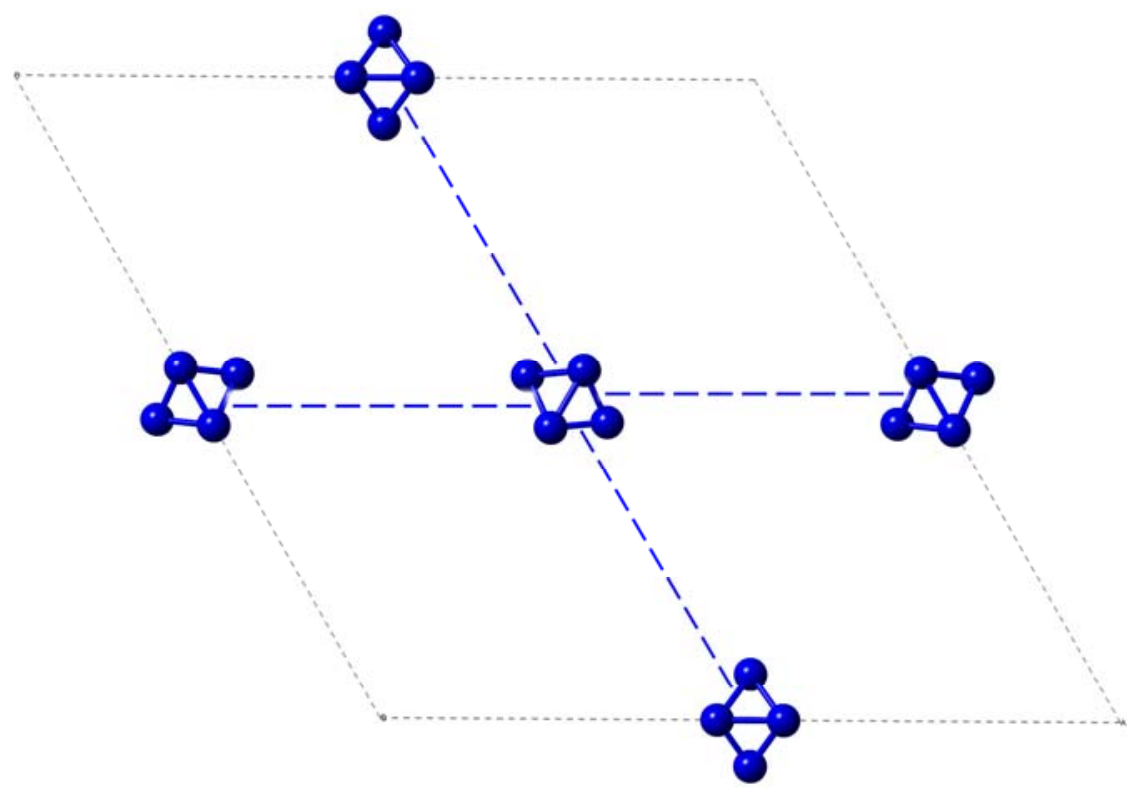

Figure S21. Orientation of the $\mathrm{M}_{6}(\mathrm{O})_{8}$ nodes in a) UiO-66 and b) NU-1000 frameworks. Dash lines in blue represent the directions along which the linker linearly connect the nodes. 


\section{References}

(1) Mondloch, J. E.; Bury, W.; Fairen-Jimenez, D.; Kwon, S.; DeMarco, E. J.; Weston, M. H.; Sarjeant, A. A.; Nguyen, S. T.; Stair, P. C.; Snurr, R. Q.; Farha, O. K.; Hupp, J. T. J. Am. Chem. Soc. 2013, 135, 10294.

(2) Beyzavi, M. H.; Klet, R. C.; Tussupbayev, S.; Borycz, J.; Vermeulen, N. A.; Cramer, C. J.; Stoddart, J. F.; Hupp, J. T.; Farha, O. K. J. Am. Chem. Soc. 2014, 136, 15861.

(3) Katz, M. J.; Brown, Z. J.; Colon, Y. J.; Siu, P. W.; Scheidt, K. A.; Snurr, R. Q.; Hupp, J. T.; Farha, O. K. Chem. Commun. 2013, 49, 9449.

(4) Jakobsen, S.; Gianolio, D.; Wragg, D. S.; Nilsen, M. H.; Emerich, H.; Bordiga, S.; Lamberti, C.; Olsbye, U.; Tilset, M.; Lillerud, K. P. Phys. Rev. B 2012, 86, 125429.

(5) Kickelbick, G.; Wiede, P.; Schubert, U. Inorganica Chimica Acta 1999, $284,1$.

(6) Planas, N.; Mondloch, J. E.; Tussupbayev, S.; Borycz, J.; Gagliardi, L.; Hupp, J. T.; Farha, O. K.; Cramer, C. J. J. Phys. Chem. Lett. 2014, 5, 3716.

(7) Perdew, J. P.; Burke, K.; Ernzerhof, M. Phys. Rev. Lett. 1996, 77, 3865.

(8) TURBOMOLE V6.6 a development of University of Karlsruhe and Forschungszentrum Karlsruhe $\mathrm{GmbH},-.$, TURBOMOLE GmbH, since 2007; available from http://www.turbomole.com . 2014.

(9) Andrae, D.; Häußermann, U.; Dolg, M.; Stoll, H.; Preuß, H. Theoret. Chim. Acta 1990, 77, 123.

(10) Weigend, F.; Ahlrichs, R. Phys. Chem. Chem. Phys. 2005, 7, 3297.

(11) Zhao, Y.; Truhlar, D. G. J. Chem. Phys. 2006, 125, 194101.

(12) Kresse, G.; Furthmuller, J. Comp. Mater. Sci. 1996, 6, 15.

(13) Kresse, G.; Furthmuller, J. Phys. Rev. B 1996, 54, 11169.

(14) Jain, A.; Ong, S. P.; Hautier, G.; Chen, W.; Richards, W. D.; Dacek, S.; Cholia, S.; Gunter, D.; Skinner, D.; Ceder, G.; Persson, K. A. APL Mater. 2013, 1, 011002. 